\title{
Dialyzer and Machine Technologies: Application of Recent Advances to Clinical Practice
}

\author{
Richard A. Ward ${ }^{\mathrm{a}}$ Claudio Ronco $^{\mathrm{b}}$ \\ a Department of Medicine, University of Louisville, Louisville, Ky., USA; \\ ${ }^{b}$ Department of Nephrology, St. Bortolo Hospital, Vicenza, Italy
}

\section{Key Words}

Ultrafiltration rate $\cdot$ Dialysis machines $\cdot$ Solute

clearance Blood flow rate

\begin{abstract}
Although hemodialysis is a mature therapy, a growing population of patients with more complex medical problems and limitations on resources will require technological innovations to improve the safety, reliability and efficiency of the therapy. The past several years have seen design changes to dialyzers that have provided incremental improvements in small solute clearance and more substantial improvements in the clearance of large solutes. New functions have been added to dialysis machines that help ensure reliable delivery of the dialysis prescription and enable full advantage to be taken of improvements in dialyzer clearance of large molecules. In addition, feedback control systems have been developed that may help reduce the untoward side effects which many patients experience during hemodialysis. Whether or not a particular innovation enters routine clinical use will depend on demonstrating that it improves clinical outcomes, its cost, and, in some cases, on a more enlightened approach by regulatory authorities.
\end{abstract}

Copyright @ 2006 S. Karger AG, Basel

\section{KARGER}

Fax +41613061234 E-Mail karger@karger.ch www.karger.com

\section{Introduction}

The basics of hemodialysis have been established for many years. The functions of dialyzers and dialysis machines are well defined, and in most respects, hemodialysis is a mature therapy in which major technological advances are now few and far between. Nevertheless, expansion of the dialysis population to include patients with greater comorbidities, coupled with constraints on the resources to treat these patients, continues to present opportunities for technical innovations aimed at increasing the efficiency of hemodialysis and the ease and reliability with which it is delivered. This review briefly describes some recent advances in dialyzer and dialysis machine technology with an emphasis on those that appear most likely to impact routine clinical practice.

\section{Dialyzers}

All dialyzers now in clinical use are of the hollow-fiber type with membranes of cellulose, modified cellulose or synthetic polymers [1]. The function of a dialyzer is to return the internal milieu to a more normal state through water removal and solute exchange between blood and dialysate. Water removal depends on the hydraulic permeability of the membrane. Automated ultrafiltration 
control systems are a standard feature of current dialysis machines and have eliminated the potential for excessive, uncontrolled ultrafiltration. Thus, the hydraulic permeability of the membrane is no longer an issue in the clinical use of modern dialyzers. With hydraulic permeability no longer a concern, membrane manufacturers have been free to engineer membranes to maximize solute exchange.

Solute transfer in hemodialysis is determined by the diffusive and convective permeability of the membrane - defined by the mass transfer coefficient $\left(\mathrm{K}_{\mathrm{O}}\right)$ and the sieving coefficient, respectively - the membrane surface area (A), and the blood and dialysate flow rates [1]. The $\mathrm{K}_{\mathrm{O}}$ is a composite parameter that incorporates the resistances to mass transfer associated with the membrane and the fluid boundary layers on the blood and dialysate sides of the membrane.

\section{Clearance of Small Solutes}

For small solutes, membrane resistance is now at a level where fluid boundary layers are significant contributors to $\mathrm{K}_{\mathrm{O}}$. There has been little effort at technological innovation to decrease boundary layer resistance on the blood side of the membrane. In contrast, several design changes have been introduced to decrease dialysate side resistance. These changes, aimed at improving the flow distribution of dialysate through the fiber bundle in response to the observation that $\mathrm{K}_{\mathrm{O}} \mathrm{A}$ increases as the dialysate flow rate increases [2], include optimization of fiber packing density, use of spacer yarns [3], fiber undulations [3], and new flow distributor designs [4]. These changes have improved clearances of small solutes. However, the increases are small - generally less than $10 \%$ - reflecting the dominant role that blood flow rate plays in determining the clearance of small solutes [1]. Additionally, the impetus for increasing small molecule clearance may be lessened by the HEMO study, which showed no significant improvement in outcomes when the single pool Kt/V for urea was increased from 1.25 to 1.65 [5].

\section{Clearance of Large Solutes}

It is generally accepted that uremic toxins cover a wide molecular weight range. In contrast to the failure of increased urea removal to improve outcomes, the results of the HEMO study suggest that increased removal of larger molecules - as represented by $\beta_{2}$-microglobulin - is associated with less cardiovascular mortality, the leading cause of death for hemodialysis patients [6]. Removal of higher molecular weight solutes necessitates the use of high-flux dialyzers, since low-flux dialyzers have essen- tially no capacity to remove solutes the size of small proteins. The most common high-flux membranes have some form of polysulfone as their major component. However, there are differences in the composition and structure of various high-flux 'polysulfone' membranes, which may be associated with significant differences in performance $[7,8]$. It is not yet clear if the differences in performance arise from differences in the polymer composition of the membrane or from differences in membrane morphology. Not all dialyzer manufacturers provide data on $\beta_{2^{-}}$ microglobulin clearance in their product literature, and at the present time, it is up to users to determine if they are selecting a dialyzer that provides the best possible removal of large molecular weight solutes.

Removal of large molecular weight solutes by high-flux membranes is enhanced when the treatment includes convection, either as the sole means of solute removal (hemofiltration) or in combination with diffusion (hemodiafiltration) [9]. Convection provides more removal of large molecules than diffusion because the sieving coefficient decreases more gradually with increasing molecular size than does $\mathrm{K}_{\mathrm{O}}$ [10]. Convective therapies are performed most efficiently when replacement solution is prepared on-line. Equipment to perform on-line therapies is widely available, with the notable exception of the United States. In the absence of purpose-designed equipment, the advantages of convection may be partially realized by maximizing internal filtration and back-filtration in the dialyzer. Internal filtration and back-filtration occur when membranes of high water permeability are used with a volume control system, because the low transmembrane pressure required for fluid removal and the counter-current flow of blood and dialysate in a dialyzer create local pressure gradients favoring filtration from blood to dialysate at the blood inlet end of the dialyzer and back-filtration from dialysate to blood at the blood outlet of the dialyzer. Internal filtration can be increased by using smaller diameter fibers to increase the pressure at the blood inlet. Ronco et al. [11] observed an increase of more than $30 \%$ in the removal of larger molecules, such as vitamin $B_{12}$ and inulin, when the internal diameter of the fibers was decreased from 200 to $175 \mu \mathrm{m}$.

While newer high-flux dialyzers offer increased clearances for large molecular weight solutes, particularly when used in a therapy with convection, there may be a limit to the benefits that accrue from their use because of limitations imposed by intra-body mass transfer [12]. When mass transfer in the body becomes limiting, changing treatment time and frequency will be more important than increasing clearance. 
A recent development has been the introduction of protein-leaking membranes for hemodialysis. These membranes allow the passage of larger molecules than do traditional high-flux membranes at the cost of some albumin loss. Preliminary clinical studies suggest that use of protein-leaking membranes may aid in anemia correction, reduce hyperhomocysteinemia, and reduce plasma concentrations of glycosylated and oxidized proteins [13]. None of these potential advantages have been demonstrated in a large-scale randomized clinical trial and, to date, there is no evidence of improved clinical outcomes. Accordingly, protein-leaking membranes must be considered experimental and not ready for routine clinical use.

\section{Dialysis Machines}

Dialysis machines have three basic functions: (1) circulation of blood from the patient's access through the dialyzer and back to the access using a blood pump and a disposable tubing set; (2) preparation of dialysate from purified water and one or more concentrates and circulation of that dialysate through the dialyzer using a system that also controls the rate of fluid removal, and (3) monitoring for any loss of integrity in either the blood or dialysate circuit or any excursion of an operating parameter outside a predefined range. The basic systems that provide these functions have been well established for more than 15 years and are described elsewhere [14]. Developments in dialysis machines over the past 10 years have been directed at improving dialysis efficiency and at improving safety and ease of use.

\section{Efficiency of Dialysis}

As described earlier, small solute clearance is mostly dependent on the blood and dialysate flow rates. It has long been known that the flow rate produced by the type of peristaltic pump used in the blood circuit is influenced by the inlet pressure to the pump. As the pressure decreases, the pump segment of the tubing exhibits incomplete elastic recoil resulting in a decrease in the cross-sectional area of the pump segment [15]. Since the blood flow rate displayed by dialysis machines is determined by the number of pump revolutions and the stroke volume, which is the product of the length and cross-sectional area of the pump segment, actual blood flow rates may be substantially lower than displayed blood flow rates [15]. This discrepancy can lead to underdelivery of the dialysis prescription. Two approaches have been taken to address this problem. Some dialysis machines now display blood flow rates corrected for the pressure at the pump inlet using a software algorithm. Recently, a new blood tubing set that is less pressure sensitive has been introduced [16]. The pump segment of this tubing set is more elastic and undergoes more complete recoil than traditional tubing sets.

In addition to concerns about the accuracy of the displayed blood flow rate, the effective blood flow rate may be lower than the pumped blood flow rate because of access recirculation. Access recirculation occurs when the blood flow entering the access from the systemic circulation is insufficient to provide the chosen extracorporeal blood flow rate. When that occurs, some of the blood returning to the access from the dialyzer is immediately recycled back to the dialyzer. Traditionally, access recirculation was determined from blood urea concentrations in the extracorporeal circuit and the systemic circulation. This method has several drawbacks; it may be confounded by cardiopulmonary recirculation and it may require several days to obtain the necessary urea concentrations from a clinical laboratory. An alternative approach to monitoring access performance is to measure the access blood flow rate [17]. Access blood flow rate can be measured using indicator dilution methods [18]. This technique provides a reliable estimate of access blood flow rate but requires additional equipment. Access blood flow rate can also be calculated from clearances measured with the blood lines in the normal configuration and in a reverse configuration $[19,20]$. This method has the advantage that several dialysis machines now allow the automated non-invasive measurement of ionic clearance based on dialysate conductivity measurements [21,22].

Another check on the delivery of the dialysis prescription is available through the on-line measurement of $\mathrm{Kt} / \mathrm{V}$. Early devices for measuring $\mathrm{Kt} / \mathrm{V}$ used on-line urea sensors. Acceptance of these devices for routine clinical use was poor, possibly because of the requirement for frequent calibration or the additional expenses for disposables. The development of integrated systems that measure ionic clearance $[21,22]$ has largely circumvented these problems. Ionic clearance is essentially sodium clearance, which is in turn almost equal to urea clearance. Sequential ionic clearances are used to determine a timeaveraged clearance for the treatment, which is used to calculate $\mathrm{Kt} / \mathrm{V}$ based on an estimate of the urea distribution volume entered by the operator.

Taken together, accurate knowledge of the extracorporeal blood flow rate, the ability to easily assess blood access flow rate and simple on-line estimation of $\mathrm{Kt} / \mathrm{V}$ can help assure that the dialysis prescription is actually and routinely delivered. 
As described above, it is generally accepted that large molecular weight solute removal is an important therapeutic goal. Removal of these solutes is enhanced when convection is used as in hemofiltration or hemodiafiltration. Both therapies require large volumes of replacement solution to maintain fluid balance. Early efforts at hemofiltration and hemodiafiltration were hindered by the need for large volumes of prepackaged replacement solution. This problem has been overcome by the development of dialysis machines that prepare replacement solution on-line by sequential ultrafiltration of dialysate [23]. Machines incorporating this technology have now been used to perform routine hemofiltration and hemodiafiltration in large numbers of patients.

\section{Safety and Ease of Use}

In addition to machine developments directed at improving the efficiency of hemodialysis, other developments offer advances in terms of safety, reliability and the ease with which treatments are performed. The recognition that microbiological impurities in dialysate may have adverse consequences for patients through their ability to stimulate chronic inflammation [24] has led to changes designed to provide a dialysate of high microbiological purity, often referred to as ultrapure dialysate. These developments include dry concentrate systems that prepare bicarbonate concentrate on-line, thereby minimizing the well-known problem of bacterial proliferation in bicarbonate concentrate, the incorporation of ultrafilters that provide point-of-use filtration of the dialysate immediately before it enters the dialyzer, and improvements in the design of fluid pathways of machines to eliminate areas that are difficult to disinfect. In addition to reducing morbidity in routine hemodialysis, the availability of ultrapure dialysate has been essential for the development of on-line convective therapies [23].

Many patients experience hypotension, cramps, nausea and vomiting during dialysis. These events are unpleasant for the patient and may compromise delivery of the dialysis prescription and disrupt the efficient operation of the dialysis unit. The reduction in blood volume that occurs when the ultrafiltration rate exceeds the rate of refilling from the interstitium is one factor in the development of hypotension. Dialysis machines have long been capable of varying - or profiling - the ultrafiltration rate or dialysate sodium concentration during dialysis in an attempt to limit the change in blood volume. Generally, profiling ultrafiltration and dialysate sodium has not proven to be an effective strategy for reducing intradialytic symptoms, possibly because of physiological differ- ences between patients and from treatment-to-treatment for a given patient. Several new technical innovations have been introduced aimed at addressing this ongoing problem. On-line measurements using optical density or sound velocity are used to follow relative changes in blood volume during dialysis. In their most sophisticated form, on-line measurements are used in a closed loop system to control fluid removal. Two closed loop systems are available $[25,26]$. One system adjusts the ultrafiltration rate and the dialysate composition to provide a certain trajectory for the change in blood volume during dialysis [25], while the other system regulates the ultrafiltration rate to maintain the relative blood volume above a predefined critical value [26]. Clinical trials have shown that the use of these devices is associated with a reduction in symptoms in patients both prone and not prone to hypotension $[27,28]$.

A second approach to reducing intradialytic symptoms is based on the well-established link between hypotension and dialysate temperature. By monitoring the temperature in the arterial and venous blood lines, a patient's thermal energy balance during dialysis can be determined and controlled by adjusting the dialysate temperature using a closed loop system comprising a blood temperature monitor coupled to the dialysate temperature controller [29]. In a randomized cross-over clinical trial, the use of this system to maintain a constant body temperature (isothermic dialysis) was associated with significantly less hypotension compared with hypotension when the dialysate temperature was adjusted to prevent any exchange of energy (thermoneutral dialysis) [30].

\section{Summary}

Technical innovation continues to occur in hemodialysis. While not as profound as the introduction of automated volume control systems or the reintroduction of bicarbonate-containing dialysate, recent developments in dialyzers and dialysis machines have the potential to improve the efficiency of the therapy, particularly regarding large molecule removal. They may also improve the reliability and safety of the therapy. Whether or not a particular innovation enters routine clinical use will depend on a convincing demonstration of its improvements in clinical outcomes and cost, and, in some cases, on the willingness of regulatory authorities to approve more highly automated systems including feedback control loops and the on-line preparation of replacement solution for convective therapies. 


\section{References}

1 Ronco C, Clark WR: Hollow-fiber dialyzers: technical and clinical considerations; in Nissenson AR, Fine RN (eds): Clinical Dialysis, ed 4. New York, McGraw-Hill, 2005, pp 85100.

-2 Leypoldt JK, Cheung AK, Agodoa LY, Daugirdas JT, Greene T, Keshaviah PR: Hemodialyzer mass transfer-area coefficients for urea increase at high dialysate flow rates. Kidney Int 1997;51:2013-2017.

- 3 Ronco C, Brendolan A, Crepaldi C, Rodighiero M, Scabardi M: Blood and dialysate flow distributions in hollow-fiber hemodialyzers analyzed by computerized helical scanning technique. J Am Soc Nephrol 2002;13:S53-S61.

-4 Ronco C, Bowry SK, Brendolan A, Crepaldi C, Soffiati G, Fortunato A, Bordoni V, Granziero A, Torsello G, La Greca G: Hemodialyzer: from macro-design to membrane nanostructure; the case of the FX-class of hemodialyzers. Kidney Int 2002;61(suppl 80):S126-S142.

-5 Eknoyan G, Beck GJ, Cheung AK, Daugirdas JT, Greene T, Kusek JW, Allon M, Bailey J, Delmez JA, Depner TA, Dwyer JT, Levey AS, Levin NW, Milford E, Ornt DB, Rocco MV, Schulman G, Schwab SJ, Teehan BP, Toto R: Effect of dialysis dose and membrane flux in maintenance hemodialysis. N Engl J Med 2002;347:2010-2019.

6 Cheung AK, Levin NW, Greene T, Agodoa L, Bailey J, Beck G, Clark W, Levey AS, Leypoldt JK, Ornt DB, Rocco MV, Schulman G, Schwab S, Teehan B, Eknoyan G: Effects of high-flux hemodialysis on clinical outcomes: results of the HEMO study. J Am Soc Nephrol 2003; 14 : 3251-3263.

-7 Hoenich NA, Stamp S: Clinical performance of a new high-flux synthetic membrane. Am J Kidney Dis 2000;36:345-352.

8 Ward RA, Ouseph R, Utz J: Comparison of solute removal by high-flux dialyzers containing membranes of nominally similar synthetic polymers. Nephrol Dial Transplant 2005;20 (suppl 5):v118.

-9 Ledebo I: Principles and practice of hemofiltration and hemodiafiltration. Artif Organs 1998; 22:20-25.
10 Leypoldt JK: Solute fluxes in different treatment modalities. Nephrol Dial Transplant 2000;15(suppl 1):3-9.

11 Ronco C, Brendolan A, Lupi A, Metry G, Levin NW: Effects of reduced inner diameter of hollow fibers in hemodialyzers. Kidney Int 2000;58:809-817.

12 Ward RA, Greene T, Hartman B, Samtleben $\mathrm{W}$ : Resistance to intercompartmental mass transfer limits $\beta_{2}$-microglobulin removal by post-dilution hemodiafiltration. Kidney Int, in press.

13 Ward RA: Protein-leaking membranes for hemodialysis: a new class of membranes in search of an application? J Am Soc Nephrol 2005; 16 : 2421-2430.

14 Polaschegg HD, Levin NW: Hemodialysis machines and monitors; in Jacobs C, Kjellstrand CM, Koch KM, Winchester JF (eds): Replacement of Renal Function by Dialysis, ed 4. Dordecht, Kluwer, 1996, pp 333-379.

15 Depner TA, Rizwan S, Stasi TA: Pressure effects on roller pump blood flow during hemodialysis. ASAIO Trans 1990;31:M456-M459.

16 Ahmed J, Besarab A, Lubkowski T, Frinak S: Effect of differing blood lines on delivered blood flow during hemodialysis. Am J Kidney Dis 2004;44:498-508.

17 Schwab SJ, Oliver MJ, Suhocki P, McCann R: Hemodialysis arteriovenous access: detection of stenosis and response to treatment by vascular access blood flow. Kidney Int 2001;59: 358-362.

18 Depner TA, Krivitski NM: Clinical measurement of blood flow in hemodialysis access fistulae and grafts by ultrasound dilution. ASAIO J 1995;41:M745-M749.

19 Gotch FA, Buyaki R, Panlilio F, Folden T: Measurement of blood access flow rate during hemodialysis from conductivity dialysance. ASAIO J 1999;45:139-146.

20 Mercadal L, Hamani A, Béné B, Petitclerc T: Determination of access blood flow from ionic dialysance: theory and validation. Kidney Int 1999;56:1560-1565.

21 Polaschegg HD: Automatic, noninvasive intradialytic clearance measurement. Int J Artif Organs 1993;16:185-191.
22 Petitclerc T, Goux N, Reynier AL, Béné B: A model for non-invasive estimation of in vivo dialyzer performances and patient's conductivity during hemodialysis. Int $\mathbf{J}$ Artif Organs 1993;16:585-591.

23 Ledebo I: On-line preparation of solutions for dialysis: practical aspects versus safety and regulations. J Am Soc Nephrol 2002;13:S78S83.

24 Ward RA: Ultrapure dialysate. Semin Dial 2004;17:489-497.

-25 Ronco C, Brendolan A, Milan M, Rodeghiero MP, Zanella M, La Greca G: Impact of biofeedback-induced cardiovascular stability on hemodialysis tolerance and efficiency. Kidney Int 2000;58:800-808.

26 Kraemer M: New strategies for reducing intradialytic symptoms. Semin Dial 1999;12:389395.

- 27 Santoro A, Mancini E, Basile C, Amoroso L, Di Giulio S, Usberti M, Colasanti G, Verzetti G, Rocco A, Imbasciati E, Panzetta G, Bolzani R, Grandi F, Polacchini M: Blood volume controlled hemodialysis in hypotension-prone patients: a randomized, multicenter controlled trial. Kidney Int 2002;62:1034-1045.

28 McIntyre CW, Lambie SH, Fluck RJ: Biofeedback controlled hemodialysis (BF-HD) reduces symptoms and increases both hemodynamic tolerability and dialysis adequacy in non-hypotension prone stable patients. Clin Nephrol 2003;60:105-112.

-29 Kaufman AM, Morris AT, Lavarias VA, Wang Y, Leung JF, Glabman MB, Yusuf SA, Levoci AL, Polaschegg HD, Levin NW: Effects of controlled blood cooling on hemodynamic stability and urea kinetics during high-efficiency hemodialysis. J Am Soc Nephrol 1998;9:877883.

30 Maggiore Q, Pizzarelli F, Santoro A, Panzetta G, Bonforte G, Hannedouche T, Alvarez de Lara MA, Tsouras I, Loureiro A, Ponce P, Sulkovà S, Van Roost G, Brink H, Kwan JTC: The effects of control of thermal balance on vascular stability in hemodialysis patients: results of the European randomized clinical trial. Am J Kidney Dis 2002;40:280-290. 